\title{
Supply Chain Risk Management in Automotive Small and Medium Enterprises in Malaysia
}

\author{
NORLAILE Salleh Hudin ${ }^{1, a}$, ABU BAKAR Abdul Hamid ${ }^{2, b}$ \\ ${ }^{1}$ Universiti Pendidikan Sultan Idris, Malaysia \\ ${ }^{2}$ International Business School, Universiti Teknologi Malaysia, Malaysia \\ alaile_sh@yahoo.com, bm-abakar@utm.my
}

Keywords: Supply chain, risk management practices, risks, Malaysian automotive industry

\begin{abstract}
The current automotive supply chain is facing more risks than ever due to the heavy dependencies of local automotive component manufacturers with foreign and established global producers. In response, this paper is designed to explore the supply chain risk management (SCRM) practice of automotive industry in Malaysia. In-depth case studies were conducted at two automotive components manufacturers based on three constructs of SCRM framework including the SCRM process, tools used in SCRM and techniques to minimize risk. The case studies revealed that the automotive companies implemented failure mode and effect analysis (FMEA), 5 why analysis, aspect-impact study, and recovery planning to manage their supply chain risks. In addition, brainstorming techniques, experience and expert judgment were mainly used as risk identification and assessment tools. Most of the risks encountered during operations were dealt by reactive strategies such as back-up suppliers and increasing buffer stocks. Overall, the automotive companies are heading towards more formal and sophisticated SCRM especially with the certification of TS16949 although there are still plenty of rooms for improvements in the risk identification and risk assessment tools since very limited quantitative techniques were evidenced.
\end{abstract}

\section{Introduction}

The automotive supply chains have been proven to be facing risks derived from globalisation, increasing outsoucing activities and product variants [1], and supplier default [2] which threatened the flow of finished product or material supplies. For that reason, major automotive companies have increased their supply chain risk management (SCRM) activities for example by mapping their supply chains to identify the weak links [3]. Nevertheless, a review of SCRM studies from 1995 until 2009 indicated that the study of SCRM implementation were limited in the current literature [4]. A study in German automotive industry also indicated that surveys of SCRM implementation in other countries were lacking [5]. Thus, the objective of this paper is to explore the supply chain risk management (SCRM) practice of automotive industry in Malaysia. This paper begins with the review of past studies of SCRM implementation in automotive industry and a clarification of SCRM construct. The methodology applied follows and next the findings, discussion and conclusion are presented.

\section{Literature Review}

SCRM Implementation in Automotive Industry. A study of automotive companies in Brazil revealed three major practices were often associated with SCRM including (1) better supply chain communication, (2) SCRM and business continuity management training program, and (3) the creation of chief risk officer (CRO) [6]. Moreover, they had their suppliers located nearby their plants to maintain ongoing supplies despite of complex production forecast. Although these companies were vulnerable to debt and credit, union regulation, property damage and theft risks, surprisingly, most of the respondents strongly disagreed that they have to develop risk assessment 
and contingency plan. In German, a research confirmed that most of the automotive companies implemented preventive instruments more often than reactive instruments to minimize risks [5]. Another study found that preventive instruments were significantly preferred by large scale automotive companies whereas SMEs preferred reactive instruments [1]. This result indicated that SMEs were more likely to absorb the impact of risks while large scale companies systematically eliminated or reduced the possibility of risk occurrence.

SCRM Constructs. In order to explore the implementation of SCRM practices, three constructs proposed by earlier studies are utilized. The first construct is SCRM process [7,8]. With specific reference to SMEs, SCRM process comprises (1) risk identification, (2) risk assessment, and (3) risk mitigation [9]. Although the application of SCRM process is frequently encouraged by international standards and scholarly articles, some companies still implement SCRM implicitly [10]. The second construct is tools for identifying and assessing supply chain risks [11]. The most commonly used tools were all qualitative; checklist and brainstorming as risk identification techniques whereas observation, intuition, experience and judgments were widely used as risk assessment techniques [12,13]. Although these qualitative tools have been critized [14,15], however, the widespread use of qualitative tools persists. The last construct refers to techniques to minimize risk [16]. While several researchers broadly categorized the techniques into risk reduction and buffering strategies [17], others called them preventive and reactive strategies respectively $[1,6]$.

\section{Methodology}

Malaysian automotive industry is chosen for this study because it relies on the same suppliers as other supply chains in different countries thus exposing it to similar set of risks. The data were gathered from March until June 2014 by means of case study approach. Series of interviews were conducted with senior managers, purchasing, logistics and production engineers at two automotive SMEs. The informants have work experience between 6 to 23 years at the respective companies. The data also comprise print documentation and observation to achieve the research validity and reliability. In all, a total of 8 interviews were conducted at these companies as the data reached saturation. The data were analysed by using thematic analysis to capture the latent and contextual meaning. The analysis was started by transcribing the interviews and followed by coding, categorizing and interpreting the data.

\section{Findings}

Background of Company A. Company A is a manufacturer of high consistent quality gasket which is fully owned by Japanese shareholders. It was established in 1990. Their main clients among other are Mitsubishi, Mazda, Kawasaki, Jatco, Sanden, Daihatsu, Proton, Perodua and Toyota. Their suppliers are mostly from Malaysia and Japan. This company recently achieved the TS16949 certification, a quality management system certification for automotive industry developed by the Big 3 American automakers, Daimler-Chrysler, Ford Motors and General Motors.

SCRM Process at Company A. The main supply chain risk management practice is called the study of aspect-impact which is part of TS16949. The aspect-impact review meeting is carried out every quarterly, involved by all Head of Departments and chaired by the Managing Director. In the aspect-impact study, risks are assessed according to 4 aspects namely man, machine, method and material apart from the environmental aspect which they have assessed through the ISO 9001 achieved earlier. The main objectives is to ensure on time delivery and continuity of supplies to customers. The process of aspect-impact study starts with risk identification and followed by risk assessment, risk mitigation and risk monitoring. In the case where Company A has no choice but to absorb or accept the risk impacts, they perform recovery planning, which is an ad hoc meeting, 
involving related departments. With regard to production related risks such as the quality risks, a special practice called the Failure Mode and Effect (FMEA) analysis is conducted. It involves various personnel such as the engineers, production managers and quality assurance manager. It is also worth to note that lower level employees are involved as well in the FMEA.

Tools Used for Identifying and Assessing Supply Chain Risks at Company A. At company $\mathrm{A}$, the tools used for risk identification and risk assessment included qualitative and quantitative methods although the qualitative method is more commonly used. In particular, they perform their SCRM practices by using brainstorming, experience and subjective judgment. Despite the tendency to use qualitative analysis, Company A also conducted quantitative analysis whenever possible. So far, they have performed minor simulation analysis and statistical forecasting analysis to make a statistical estimation of future customers' demands.

Techniques to Minimize Risk at Company A. The most frequent techniques to minimize risks are creating one and a half month of safety stocks. Secondly, they conduct demand management where they negotiate with their customers to spread the demands across time whenever they realize that they cannot deliver the customers' orders. They also practices an open and visible supply chain where all problems encountered by their suppliers or themselves are well communicated with other parties in the supply chain impacted by the problem. Moreover, they also established contract agreement with a third party logistics company to uphold the responsibility of delivering their products on time and at the right quantity to customers because their customers will penalize them RM500 per minute of downtime. For less frequent risks especially the risk of natural disaster, they have chosen to take fewer preventive actions. One of the informants confirmed that they have not increased any effort to minimize the risk of tsunami and flood which affected their $2^{\text {nd }}$ tier supplier.

Background of Company B. Company B is a producer of car air conditioner which was established in 1985. They are also a subsidiary of Japanese firm with more than 50 percent of their parts are imported from China while the rest are either purchased from Japan, Korea, Thailand, Indonesia or Malaysia. Their main customers are Honda, Peugot and Volkswagen. Similar with Company A, this company has achieved the TS16949 certification although much earlier.

SCRM Process at Company B. Unlike Company A, only the logistic manager at Company B explained that they conducted aspect-impact study at the department level twice a month based on the 4 aspects previously discussed. Nevertheless, the aspect-impact study does not only involve top managers in the logistics department, but also the lower level employees. Other departments practice their own SCRM in accordance to the risks related to their departments. For example, the purchasing managers confirmed that the most common SCRM practice applied at her department was supplier evaluation based on quality, delivery and cost aspects. After supplier evaluation, they monitor the performance of the suppliers as a risk monitoring activity. Due to heavy reliance on suppliers in China who they claimed to have quality issues, Company B implemented FMEA involving only top managers in production, production engineering, $\mathrm{R} \& \mathrm{D}$ and quality department. Another practice to minimize the quality risk is called the 5 why analysis which is conducted as per customer requirement. Overall, they claimed that their SCRM was based on TS16949 standard.

Tools Used for Identifying and Assessing Supply Chain Risks at Company B. The tools commonly used for risk identification and risk assessment at Company B is brainstroming technique. It is applied for the aspect-impact study and the FMEA. With respect to the supplier evaluation, the subjective judgment is utilized along with past experiences of managers. Simulation analysis is also performed for production related risks.

Techniques to Minimize Risk at Company B. Risks are prevented at Company B by installing technological advancements and automation, conducting quality management program and supplier development program. However, they also keep one and a half month of safety stock, conduct daily risk meeting, hire contract workers to sort reject materials and have back-up suppliers as risk reactive strategies. 


\section{Discussion}

The results showed that these two case study companies are partially practicing formal SCRM. This result corroborates with earlier research which found SMEs' higher inclination to practice informal SCRM. SMEs have the lack of formal risk analysis [18] and inadequate risk assessment training compared to large companies [19]. Company A and B also implemented the SCRM process based on the TS16949 standard required by their customers but the tools used to perform risk identification and risk assessment are mainly qualitative and basic. Again, this finding confirms other studies who arrived at similar results [20,21]. Regarding the techniques to minimize risks, SMEs have the tendency to apply reactive or buffering strategies as explained by [1]. This is probably due to stringent financial support because the larger portion of SCRM costs goes to the risk countermeasures, as said by the informants. Hence, although the process and procedures of SCRM are established, the execution of SCRM still has a long way before it becomes completely formalized. The pattern of SCRM implementation at SMEs is also corroborate with the resource dependence theory which explains that organization act according to the demand of resource providers. In this study, large automakers select automotive SMEs that implemented SCRM to be their suppliers. Therefore, these SMEs implement SCRM practices, although not entirely a formal one primarily for supplier qualification purpose.

\section{Conclusion}

This study attempts to explore the SCRM implementation at automotive SMEs in Malaysia. The results reveal that automotive companies tend to implement informal SCRM probably due to several barriers such as limited capital. The informal SCRM is particularly characterized by the frequent use of qualitative risk identification and assessment as well as reactive strategies. The overall maturity of SCRM practices in Malaysian automotive industry could also affect the level of SCRM implementation in individual companies. For future reseach agenda, it is suggested that a survey to be conducted among automotive industry to further confirm the current results.

\section{References}

[1] J.-H. Thun, M. Druke, D. Hoenig, Managing uncertainty - An empirical analysis of supply chain risk management in small and medium-sized enterprises. International Journal of Production Research. 49, 18 (2011) 5511-5525.

[2] S. M. Wagner, C. Bode, P. Koziol, Supplier default dependencies: Empirical evidence from the automotive industry, European Journal of Operational Research. 199 (2009) 150-161.

[3] C. Jones, Business unaware of supply chain risk, Financial Times. 2013.

[4] O. Tang, S. N. Musa, Identifying risk issues and research advancements in supply chain risk management, International Journal of Production Economics. 133 (2011) 25-34.

[5] J. - H. Thun, D. Hoenig, An empirical analysis of supply chain risk management in the German automotive industry, International Journal of Production Economics. 131 (2011) 242-249.

[6] M. F. Blos, M. Quaddus, H. M. Wee, K. Watanabe, Supply chain risk management (SCRM): A case study on the automotive and electronic industries in Brazil, Supply Chain Management: An International Journal. 14, 4 (2009) 247-252.

[7] P. S. Ceryno, L. F. Scavarda, K. Klingebiel, G. Yuzgulec, Supply chain risk management: A content analysis approach, International Journal of Industrial Engineering and Management. 4, 3 (2013) 141-150. 
[8] T. Henschel, Risk Management Practice of SMEs: Evaluating and Implementing Effective Risk Management Systems, Erich Schmidt Verlag GmbH \& Co, Berlin, 2008.

[9] U. Juttner, A. Ziegenbein, Supply chain risk management for small and medium-sized, in: G. A. Zsidisin, B. Ritchie (Eds.), Supply Chain Risk: A Handbook of Assessment, Management, and Performance, Springer Science+Business Media, New York, 2009, pp. 199-216.

[10] Å. Boholm, H. Corvellec, A relational theory of risk, Journal of Risk Research. 14, 2 (2011) 175-190.

[11] U. Juttner, Supply chain risk management: Understanding the business requirements from a practitioner perspective, The International Journal of Logistics Management. 16, 1 (2005) 120-141.

[12] A. Boholm, On the organizational practice of expert-based risk management: A case of railway planning. Risk Management. 12, 4 (2010) 235-255.

[13] M. Altuntas, T. R. Berry-Stolzle, R. E. Hoyt, Implementation of enterprise risk management: Evidence from the German property-liability insurance industry, The Geneva Papers. 36, (2011) 414-439.

[14] A. Bialas, Security of Information and Services in Modern Institution, WNT, Warsaw, 2006.

[15] S. P. Bennett, M. P. Kailay, An application of qualitative risk analysis to computer security for the commercial sector. Proceedings of 8th IEEE Annual Computer Security Applications Conference, IEEE Computer Society Press. San Antonio (1992) 64-73.

[16] O. Lavastre, A. Gunasekaran, A. Spalanzani, Supply chain risk management in French companies, Decision Support Systems. 52 (2012) 828-838.

[17] G. A. Zsidisin, S. M. Wagner, S. A. Melnyk, G. L. Ragatz, L. A. Burns, Supply risk perceptions and practices: An exploratory comparison of German and US supply management professionals, International Journal of Technology, Policy and Management. 8, 4 (2008) 401-419.

[18] T. I. Vaaland, M. Heide, Can the SME survive the supply chain challenges? Supply Chain Management: An International Journal. 12, 1 (2007) 20-31.

[19] P. Finch, Supply chain risk management, Supply Chain Management: An International Journal. 9, 2 (2004) 183-196.

[20] N. Banaitiene, A. Banaitis, A. Norkus, Risk management in projects: Pecularities of Lithuanian construction companies, International Journal of Strategic Property Management. 15, 1 (2011) 6073.

[21] R. M. Choudry, K. Iqbal, Identification of risk management system in construction industry in Pakistan, Journal of Management in Engineering. 29 (2013) 42-49. 